\title{
Effect of Glyphosate Application on Foliar Diseases in Glyphosate-Tolerant Alfalfa
}

Deborah A. Samac, United States Department of Agriculture-Agricultural Research Service, Plant Science Research Unit, and Department of Plant Pathology, University of Minnesota, St. Paul 55108; and Dawn Foster-Hartnett, Department of Plant Pathology, University of Minnesota

\begin{abstract}
Samac, D. A., and Foster-Hartnett, D. 2012. Effect of glyphosate application on foliar diseases in glyphosate-tolerant alfalfa. Plant Dis. 96:11041110.

Glyphosate, the active ingredient in Roundup herbicide, inhibits 5enol-pyruvyl shikimate 3-phophate synthase (EPSPS), an enzyme found in plants, fungi, and bacteria. Plants engineered for glyphosate tolerance with a glyphosate-insensitive EPSPS take up and translocate the herbicide throughout the plant. In greenhouse experiments, we found that application of glyphosate at the recommended field application rate completely controlled alfalfa rust (Uromyces striatus) on 4week-old plants inoculated with the fungus 3 days after glyphosate treatment. Control was effective in all seven cultivars tested. The level of protection declined with time after application, indicating that con-

trol is transitory and protection declined with time after inoculation, suggesting that protective treatments have fungistatic activity. Complete control of rust was obtained when glyphosate was applied up to 10 days after inoculation with rust spores, indicating that the herbicide also has curative activity. Treatment increased protection from anthracnose, caused by Colletotrichum trifolii, a hemibiotrophic pathogen, and reduced symptom severity for spring black stem and leaf spot, caused by Phoma medicaginis, a necrotrophic pathogen. These results indicate that glyphosate could be used to help manage foliar diseases in glyphosate-tolerant alfalfa.
\end{abstract}

Foliar diseases are a serious problem for alfalfa (Medicago sativa L.) management in all areas where alfalfa is grown. Defoliation caused by foliar pathogens has been measured from 3 to $71 \%$ depending on time of year, environmental conditions, and locale $(18,22)$. In addition to yield loss, foliar diseases can reduce seed yields and forage quality (15). Fungicide treatments are cost-effective in only some years and locations $(18,22)$. The major foliar diseases of alfalfa include spring black stem and leaf spot (Phoma medicaginis), common leaf spot (Pseudopeziza medicaginis), rust (Uromyces striatus), Leptosphaerulina leaf spot (Leptosphaerulina briosiana), summer black stem and leaf spot (Cercospora medicaginis), anthracnose (Colletotrichum trifolii), and Stemphylium leaf spot (Stemphylium botryosum) $(9,10,22,27)$. Standard tests to identify resistant plants have been developed for many foliar diseases (25), and germplasm selected for enhanced resistance is available. However, foliar diseases remain problematic. The usual means of managing foliar diseases is to harvest the crop early when foliar diseases are severe, to reduce leaf loss and remove inoculum. During the growing season, alfalfa foliage is typically harvested every 25 to 35 days.

Recently, genetically modified alfalfa that is tolerant to the herbicide glyphosate was approved for sale in the United States

\section{Corresponding author: D. A. Samac, E-mail: debby.samac@ars.usda.gov}

Mention of any trade names or commercial products in this article is solely for the purpose of providing specific information and does not imply recommendation or endorsement by the United States Department of Agriculture.

Accepted for publication 27 February 2012.

http://dx.doi.org/10.1094/PDIS-08-11-0715-RE

This article is in the public domain and not copyrightable. It may be freely reprinted with customary crediting of the source. The American Phytopathological Society, 2012.
(2). To date, 38 glyphosate-tolerant varieties have been developed in fall dormancy classes 3 to 9 , with the majority of varieties available in fall dormancy class 4 (17). In alfalfa varieties, the fall dormancy classification describes growth in the fall; varieties with lower numbers have less fall growth because of decreasing temperature and day length. Laboratory and field experiments with glyphosate-tolerant wheat and soybean demonstrated that rust diseases could be controlled in glyphosate-tolerant crops by herbicide application before rust infection and, to some extent, after rust infection $(1,7,8)$. Glyphosate inactivates 5-enol-pyruvyl shikimate 3-phosphate synthase (EPSPS), the sixth enzyme in the shikimate pathway leading to production of aromatic amino acids, by binding to the enzyme-shikimate 3-phosphate complex (11). In glyphosatetolerant soybean, wheat, and alfalfa, herbicide tolerance is based on insertion of a gene encoding an insensitive form of the enzyme (6). Thus, in tolerant plants with an insensitive enzyme, glyphosate is absorbed after application and moves systemically throughout the plant (7). Concentrations within plant tissues decline gradually due to distribution and dilution with plant growth. The shikimate pathway is present in fungi, although there is clear evidence for separate evolution of the pathway enzymes in plants and fungi (21). In plants, each enzyme is encoded by a separate gene whereas, in fungi, steps two through six are catalyzed by a pentafunctional enzyme, AROM, encoded by a single gene. Inhibition of rust fungal growth on glyphosate-tolerant wheat and soybean after glyphosate application is assumed to be due to inactivation of fungal EPSPS activity $(1,7)$. Anderson and Kolmer (1) speculated that, in addition to leaf rust and stem rust, glyphosate application might control other foliar fungal pathogens in glyphosate-tolerant wheat. There are a number of reports of inhibition of fungal growth by glyphosate in vitro and after treatment of crop residues (24). However, whether control of pathogens in glyphosate-tolerant crops can be extended from biotrophs to foliar necrotrophic pathogens has not been reported.

The objective of this study was to determine whether glyphosate treatment has the potential to be used to manage foliar diseases in 
glyphosate-tolerant alfalfa by evaluating the effect of glyphosate application on symptoms caused by a biotrophic pathogen, $U$. striatus J. Schröt., the causal agent of alfalfa rust; a hemibiotrophic pathogen, $C$. trifolii Bain, which causes anthracnose; and a necrotrophic pathogen, Phoma medicaginis Malbr. \& Roum, the cause of spring black stem and leaf spot. $U$. striatus is the most common and destructive biotrophic pathogen of alfalfa and is found throughout the world (13). In the United States, it is more serious in southern states where it may remain active through the winter. Urediniospores spread north during the summer and the disease is active in northern states in late summer and autumn, with secondary spread occurring within a field. Although $U$. striatus is a macrocyclic rust, the sexual stage on Euphorbia spp. is not common and the fungus reproduces primarily by the asexual cycle (13), which requires approximately 14 days to complete depending on temperature (28). Pustules of urediniospores rupture the epidermis
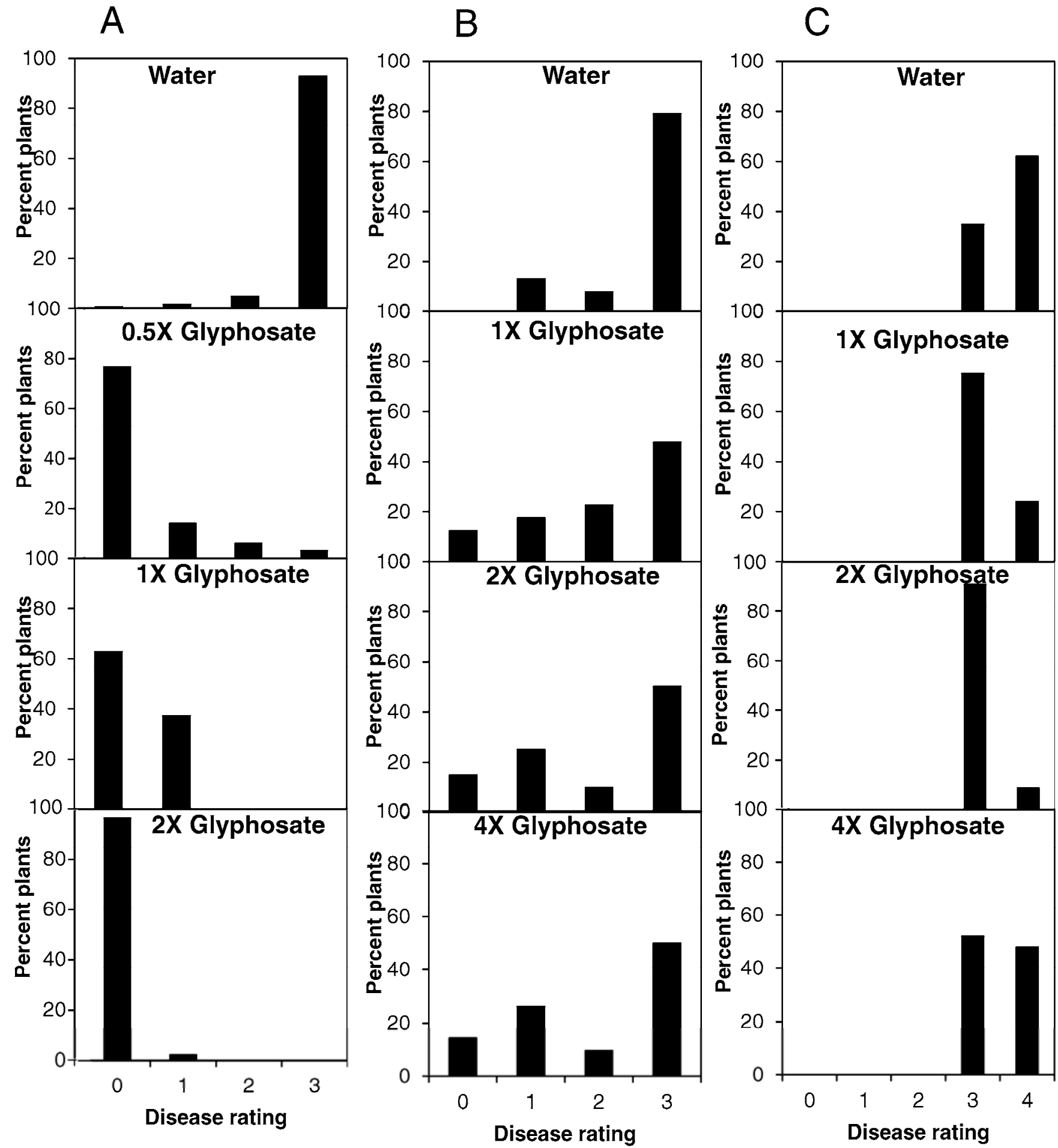

Fig. 1. Effect of glyphosate pretreatment on disease symptom expression after inoculation with rust, anthracnose, and spring black stem and leaf spot pathogens in glyphosate-tolerant alfalfa. Plants of 'DKA44-18RR' were treated with glyphosate (Roundup WeatherMax) at $0.5 \times, 1 \times, 2 \times$, or $4 \times$ the recommended field application rate or with water 3 days before pathogen inoculation. A, Frequency of disease rating scores 14 days post inoculation (dpi) with Uromyces striatus. Plants with a score of 0 or 1 were considered protected from disease; $n=135$ plants for each treatment. B, Frequency of disease rating scores 15 dpi with Colletotrichum trifolii race 2 . Plants with a score of 0 or 1 were considered protected from disease; $n=75$ plants for each treatment. C, Frequency of disease rating scores 14 dpi with Phoma medicaginis. A score of 0 or 1 was considered protected from disease, $3=$ lesions greater than $3 \mathrm{~mm}$, and $4=$ lesions greater than $3 \mathrm{~mm}$, with defoliation or dead plant; $n=75$ plants for each treatment. 
of leaves, petioles, and stems, causing leaflets to wither and fall (13). Rust can cause the loss of fall-seeded stands in the south and weaken northern plants, contributing to winterkill. Anthracnose is prevalent in the United States and many regions of the world. Several races have been identified, although race 1 is the most widespread and of most economic importance (19). In contrast to other Colletotrichum spp., a biotrophic relationship between the plant and fungus does not occur (16). Conidial germination is followed by formation of an appressorium and penetration peg in an epidermal cell. A large, ephemeral infection vesicle forms in the penetrated cell, which dies soon after vesicle formation (16). The fungus rapidly colonizes plant cells by intercellular hyphal growth, resulting in necrotic lesions. Although the pathogen can attack leaves, in the field, the most common symptoms are diamondshaped lesions on stems. $P$. medicaginis occurs in all temperate areas where alfalfa is grown. It is highly destructive in spring and fall, when cool, moist conditions occur (5). Foliar infections cause chlorosis and defoliation, stem infections can cause girdling and

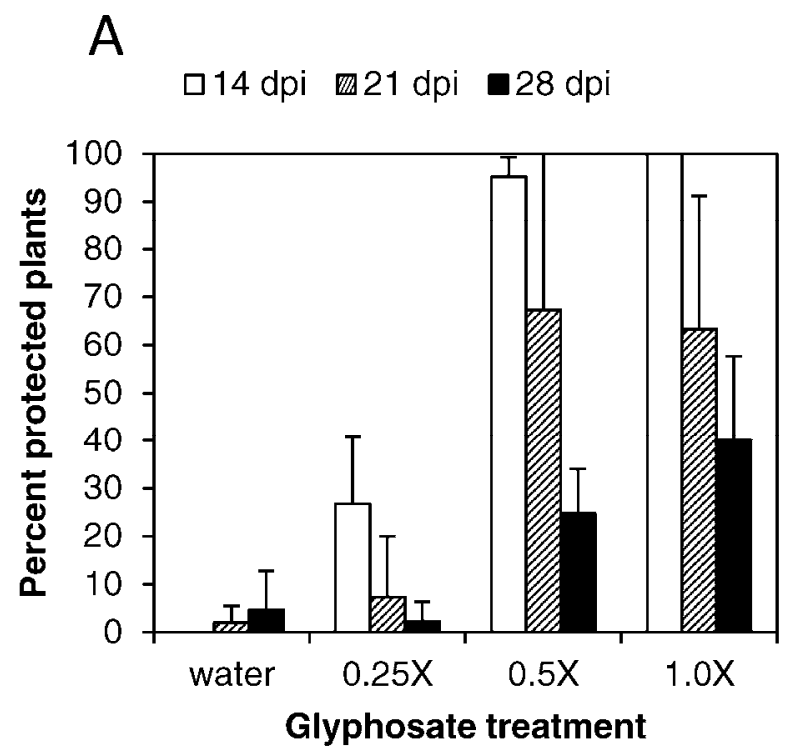

B

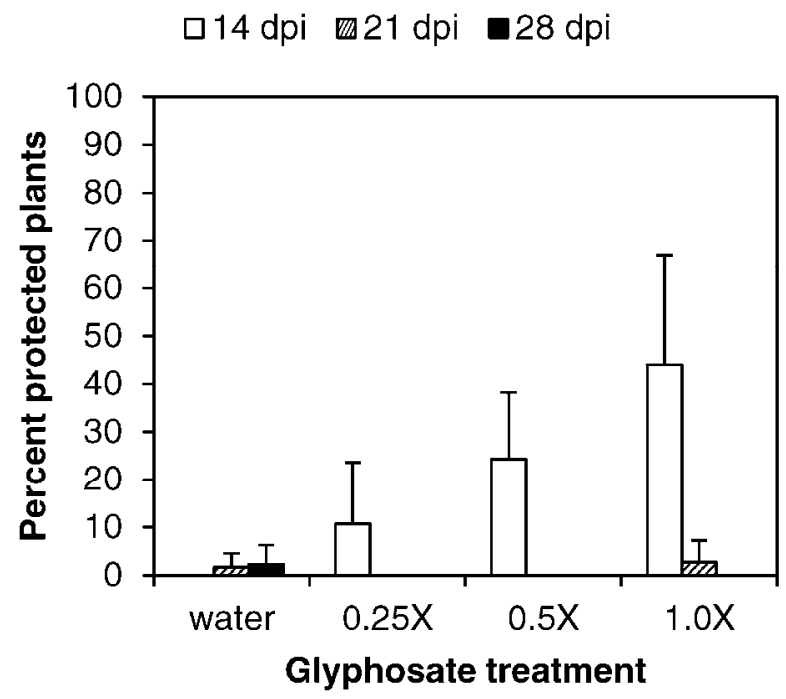

Fig. 2. Duration of rust control by glyphosate application in glyphosate-tolerant alfalfa. Four-week-old plants of the glyphosate-tolerant 'DKA44-18RR' were treated with glyphosate (Roundup WeatherMax) at $0.25 \times, 0.5 \times$, or $1 \times$ the recommended field application rate. Error bars indicate standard deviation. A disease rating score of 0 or 1 was considered to be protected from disease. A, Percent protected plants inoculated 3 days after glyphosate treatment; $n=75$ plants for each treatment at each time point. B, Percent protected plants inoculated 10 days after glyphosate treatment; $n=75$ plants for each treatment at each time point. death of stems, and crown infections lead to crown and root rot. Pycnidia that overwinter in infected plant material ooze spores that are spread primarily by splashing water but also by wind and insects. Under optimal conditions, pycnidia form and defoliation occurs in 7 to 10 days after infection (5).

If glyphosate has activity against foliar pathogens of alfalfa, it may be a useful tool for producers to manage diseases. In this study we tested (i) the efficacy of pre-inoculation glyphosate treatments for preventing symptoms of rust, anthracnose, and spring black stem and leaf spot; (ii) the longevity of pre-inoculation glyphosate treatments for control of rust; and (iii) the efficacy of post-inoculation glyphosate treatments to cure rust infection.

\section{Materials and Methods}

Plant materials and plant growth conditions. Seed of glyphosate-tolerant varieties 'DKA34-17RR' (fall dormancy 3), 'Liberator RR' (fall dormancy 4), 'Consistency RR' (fall dormancy 4), 'Revolution RR' (fall dormancy 8), 'DKA84-10RR' (fall dormancy 8), and 'WL660RR' (fall dormancy 9) were obtained from Peter Reisen, Forage Genetics International, Nampa, ID. Seed of 'DKA41-18RR' (fall dormancy 4) was provided by Paulette Pierson, Monsanto Company, St. Louis. Standard check varieties 'MSA-CW3An3' (rust resistant), 'Moapa 69' (rust susceptible), 'Saranac AR' (anthracnose resistant), 'Saranac' (anthracnose susceptible), 'Ramsey' (spring black stem and leaf spot resistant), and 'Ranger' (spring black stem and leaf spot susceptible) were obtained from JoAnn Lamb, United States Department of Agriculture-Agricultural Research Service (USDA-ARS), Saint Paul, MN.

Seed were planted in five rows in Nalgene tubs $(38 \mathrm{~cm}$ wide by $51 \mathrm{~cm}$ long by $13 \mathrm{~cm}$ deep) containing steamed soil/MetroMix 200 (2:1, vol/vol; Scotts-Sierra Horticultural Products, Marysville, $\mathrm{OH})$. Plants were grown in a greenhouse at $25^{\circ} \mathrm{C}$ with a 16 -h photoperiod. After 2 weeks, plants were thinned to 15 or 25 plants/row, fertilized with Osmocote 15-9-12 (Scotts-Sierra Horticultural Products), and treated with Marathon (1\% granular imidacloprid; Olympic Horticultural Products, Mainland, PA) to control thrips. There were three replicates arranged in a completely randomized design in each experiment and each experiment was done two to four times. Disease was scored on 12 to 16 plants grown in the three middle rows in each replicate.

Glyphosate (Roundup WeatherMax; Monsanto) was applied at $0.25 \times, 0.5 \times, 1 \times, 2 \times$, or $4 \times$ the recommended field application rate for glyphosate-tolerant plants in a volume of approximately 187 liters/ha using an overhead sprayer. The $1 \times$ rate treatment contains glyphosate at $1.7 \mathrm{~kg}$ acid equivalent/ha. Plants were not watered for $24 \mathrm{~h}$ post application. Standard check varieties included in experiments as inoculation controls were not treated with glyphosate.

Pathogen inoculation. Urediniospores of $U$. striatus were collected from field-grown plants at the Sand Plain Experimental Research Farm, Becker, MN and propagated on alfalfa plants Saranac or DKA41-18RR in the greenhouse. Spores were stored at $4^{\circ} \mathrm{C}$ for up to 8 weeks before use. Urediniospores were applied to 4week-old plants at approximately $0.03 \mathrm{mg} / \mathrm{plant}$ at a concentration of $3 \mathrm{mg} / \mathrm{ml}$ in Soltrol 170 oil (Phillips Petroleum, Bartlesville, OK) using an artist's airbrush sprayer (Paasche Airbrush Company, Harwood Heights, IL) pressurized by an air pump (138 kPa). All experiments used plants of DKA41-18RR, unless noted otherwise. Inoculated plants were incubated in a dark mist chamber at $25^{\circ} \mathrm{C}$ for $24 \mathrm{~h}$. After foliage had dried, plants were transferred back into the greenhouse. Plants were inoculated 3 days after glyphosate treatment for experiments to test the protective activity of glyphosate. Inoculations were done 10 or 17 days after glyphosate treatment to evaluate the duration of protection. In experiments testing the curative effect of glyphosate, plants were inoculated and incubated for $24 \mathrm{~h}$ in the mist chamber; then, glyphosate was applied once at $1 \times$ the recommended field application rate at 2, 4, 6, 8, 10, and 12 days post-inoculation (dpi). Rust symptoms on the most highly infected leaf on each plant were scored 14 dpi on a 0 -to-3 scale in which $0=$ no symptoms; $1=1$ to 9 small closed pustules; $2=10$ to 20 open pustules, no halos; and $3=$ more than 20 open 
pustules with necrotic or pronounced chlorotic halos. A score of 0 or 1 was considered protected from disease. In some experiments, disease scoring was done using the same rating scale at 14,21 , and 28 dpi.

C. trifolii race 2 was obtained from Nichole O'Neill, USDAARS, Beltsville, MD and was grown on potato dextrose agar (PDA) plates at room temperature. Conidia were harvested in sterile distilled water with $0.01 \%$ Tween 20 and adjusted to $2 \times 10^{6}$ conidia/ml. Six-week-old DKA44-18RR plants were treated with glyphosate at $1 \times, 2 \times$, or $4 \times$ the recommended field application rate as described above and, 3 days later, inoculated with $C$. trifolii spores sprayed to run-off with a hand-held sprayer. Plants were incubated in a dark mist chamber for $48 \mathrm{~h}$ and then moved back into the greenhouse once leaves had dried. Disease symptoms were scored 15 days dpi on a 0 -to- 4 scale, in which $0=$ no symptoms, 1 $=1$ to 10 stem lesions, $2=$ more than 10 stem lesions, $3=$ more than 10 stem lesions with apical necrosis, and $4=$ dead plant. A
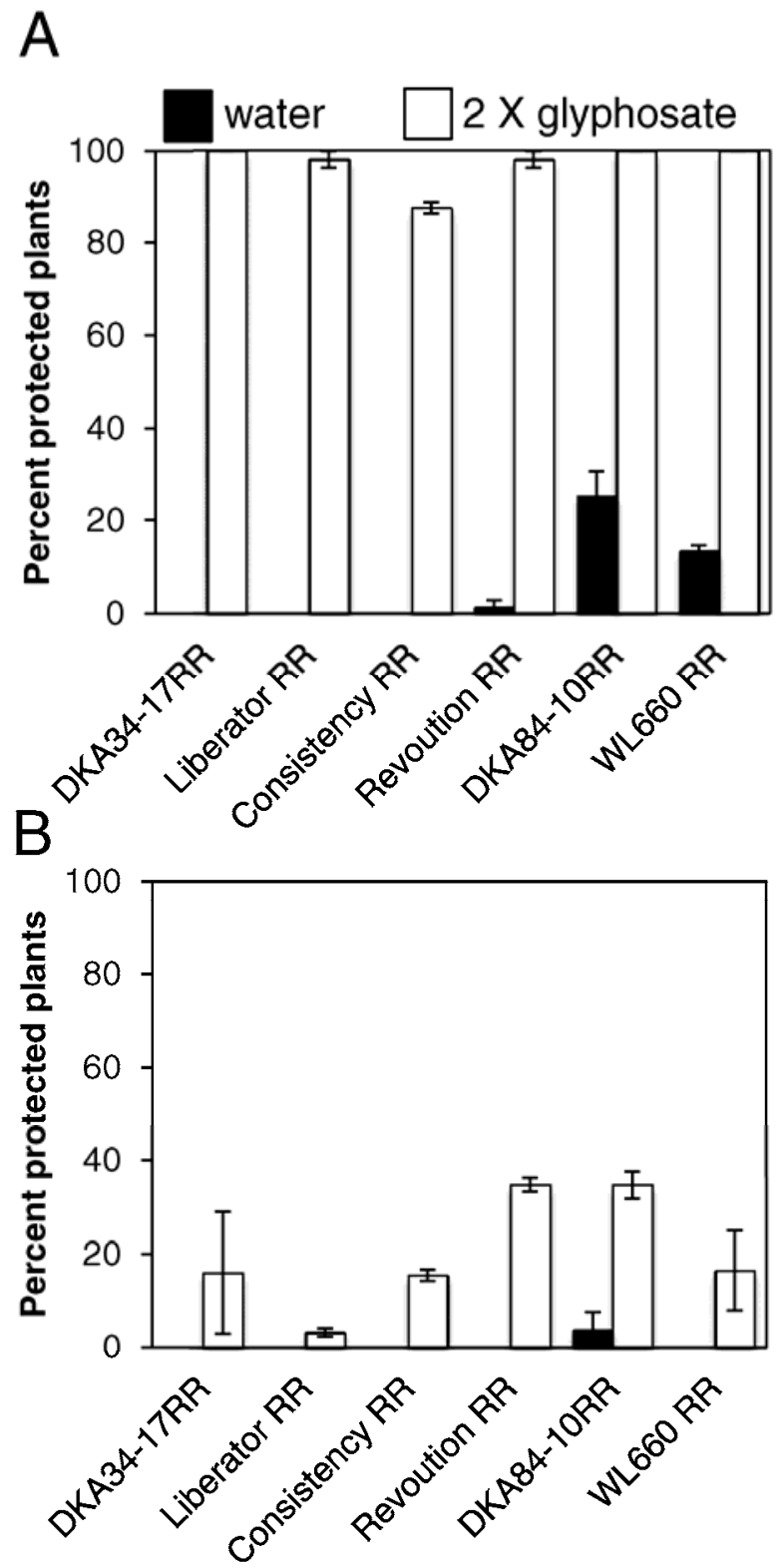

Fig. 3. Rust control in six glyphosate-tolerant alfalfa varieties differing in fall dormancy ratings. Four-week-old plants were treated with glyphosate (Roundup WeatherMax) at $2 x$ the recommended field application rate before inoculation. Plants were scored 14 days post inoculation. Error bars indicate standard deviation. A, Inoculation 3 days after glyphosate treatment; $n=75$ plants of each cultivar for each treatment. B, Inoculation 17 days after glyphosate treatment; $n=75$ plants of each cultivar for each treatment. score of 0 or 1 was considered protected from disease. DKA44$18 \mathrm{RR}$ is resistant to race 1 of $C$. trifolii but susceptible to race 2 .

P. medicaginis strain 24.2M1a was obtained from Claudia Castell-Miller, University of Minnesota, Saint Paul. Conidiospores were produced on PDA plates incubated at room temperature. The inoculum was adjusted to $1 \times 10^{6}$ spores $/ \mathrm{ml}$ in sterile water with $0.01 \%$ Tween 20 and applied to 6-week-old plants of DKA44-18RR to runoff using a hand-held sprayer. Plants were placed in a dark mist chamber for $48 \mathrm{~h}$ and then transferred back to the greenhouse after leaves had dried. Symptoms were scored 14 dpi on a 0 -to-4 scale, in which $0=$ no symptoms; $1=$ lesions less than $2 \mathrm{~mm} ; 2=$ lesions greater than $2 \mathrm{~mm}$, with necrotic centers; $3=$ lesions greater than $3 \mathrm{~mm}$; and $4=$ lesions greater than $3 \mathrm{~mm}$, with defoliation or dead plant. A score of 0 or 1 was considered protected from disease.

Statistical analysis was done using SAS software (version 9.2; SAS Institute Inc., Cary, NC). The $\chi^{2}$ analysis and Fisher's exact test for categorical data were used. A $P$ value of less than 0.05 was considered statistically significant.

\section{Results}

Glyphosate treatments were very effective in reducing rust symptoms but were less effective for reducing symptoms of anthracnose and spring black stem and leaf spot (Fig. 1). All plants receiving the $1 \times$ or $2 \times$ rate glyphosate treatments 3 days before inoculation with $U$. striatus had disease scores of 0 or 1 , considered protected from disease (Fig. 1A). Most plants (91\%) receiving the $0.5 \times$ rate glyphosate treatment were protected from disease. For control water-treated plants, $2.4 \%$ were rated as either 0 or 1 . The standard check varieties responded to inoculation as expected, with $6 \%$ of plants from susceptible Moapa 69 scored as resistant (class 0 or 1 ) and $35 \%$ of plants from resistant MSA-CW3An3 rated as resistant. The effect of glyphosate for preventing rust infection appeared to be dose dependent, with higher glyphosate concentrations resulting in a larger proportion of plants protected from disease. However, a dose-dependent response was not observed for preventing symptoms of anthracnose (Fig. 1B). There was a low frequency (13.2\%) of class 1 plants, considered resistant to anthracnose, for control water-treated plants. The combined frequency of class 0 and 1 plants was $30 \%$ for plants receiving the $1 \times$ rate glyphosate treatment and $40 \%$ for plants receiving the $2 \times$ and $4 \times$ rate treatments. No disease symptoms were observed on 12

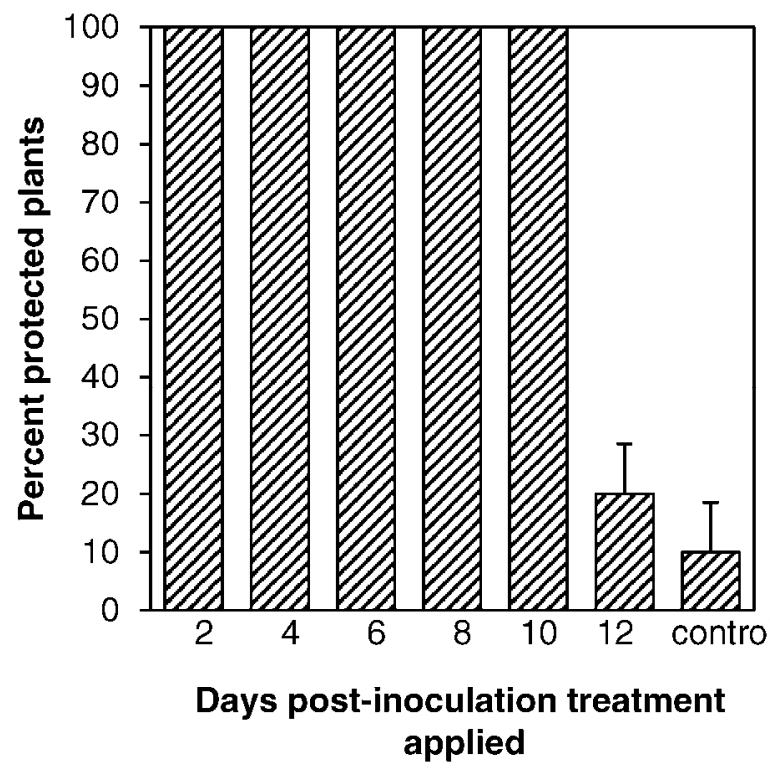

Fig. 4. Curative effect of glyphosate treatment on alfalfa rust. Four-week-old plants of 'DKA44-18RR' were treated with glyphosate at $1 \times$ the recommended field application rate at $2,4,6,8,10$, or 12 days post inoculation (dpi). Symptoms were scored at 14 dpi. The control received a water treatment with no glyphosate. Error bars indicate standard deviation. 
and $15 \%$ of plants receiving the $2 \times$ and $4 \times$ rate treatments, respectively, indicating that glyphosate provided some protection from disease. The standard check varieties responded as expected, with none of the plants of the susceptible Saranac scored as resistant and $45 \%$ of plants from the resistant check Saranac AR scored as resistant. Under the test conditions, DKA44-18RR was highly susceptible to spring black stem and leaf spot (Fig. 1C). None of the glyphosate treatments resulted in protection from disease. However, the frequency of class 4 disease scores, in which plants were defoliated or dead, was reduced by glyphosate pretreatment (Fig. 1C). All of the plants from the susceptible check Ranger had class 4 disease scores while $20 \%$ of plants from the moderately resistant check Ramsey had class 4 disease scores.
The duration of protection from rust declined over time. For plants that were treated with glyphosate 3 days before inoculation with rust, the $\chi^{2}$ test for the affect of glyphosate concentration was significant $(P<0.01)$ in all three lengths of time after treatment $(14,21$, and $28 \mathrm{dpi})$, indicating that significantly differing protection of plants from rust was obtained. The $0.25 \times$ rate glyphosate treatment provided a low amount of protection with $26 \%$ of plants scored as protected (class 0 and 1) at 14 dpi (Fig. 2A). The $0.5 \times$ and $1 \times$ rate treatments provided higher levels of protection $(95$ and $100 \%$, respectively) at $14 \mathrm{dpi}$. When disease ratings were made at 21 and $28 \mathrm{dpi}$, the proportion of plants scoring as 0 or 1 was lower than at $14 \mathrm{dpi}$ for all glyphosate treatments. For plants inoculated 10 days after the glyphosate application, the $\chi^{2}$ test for the affect of glyphosate concentration was significant $(P<0.01)$ only at 14 dpi.

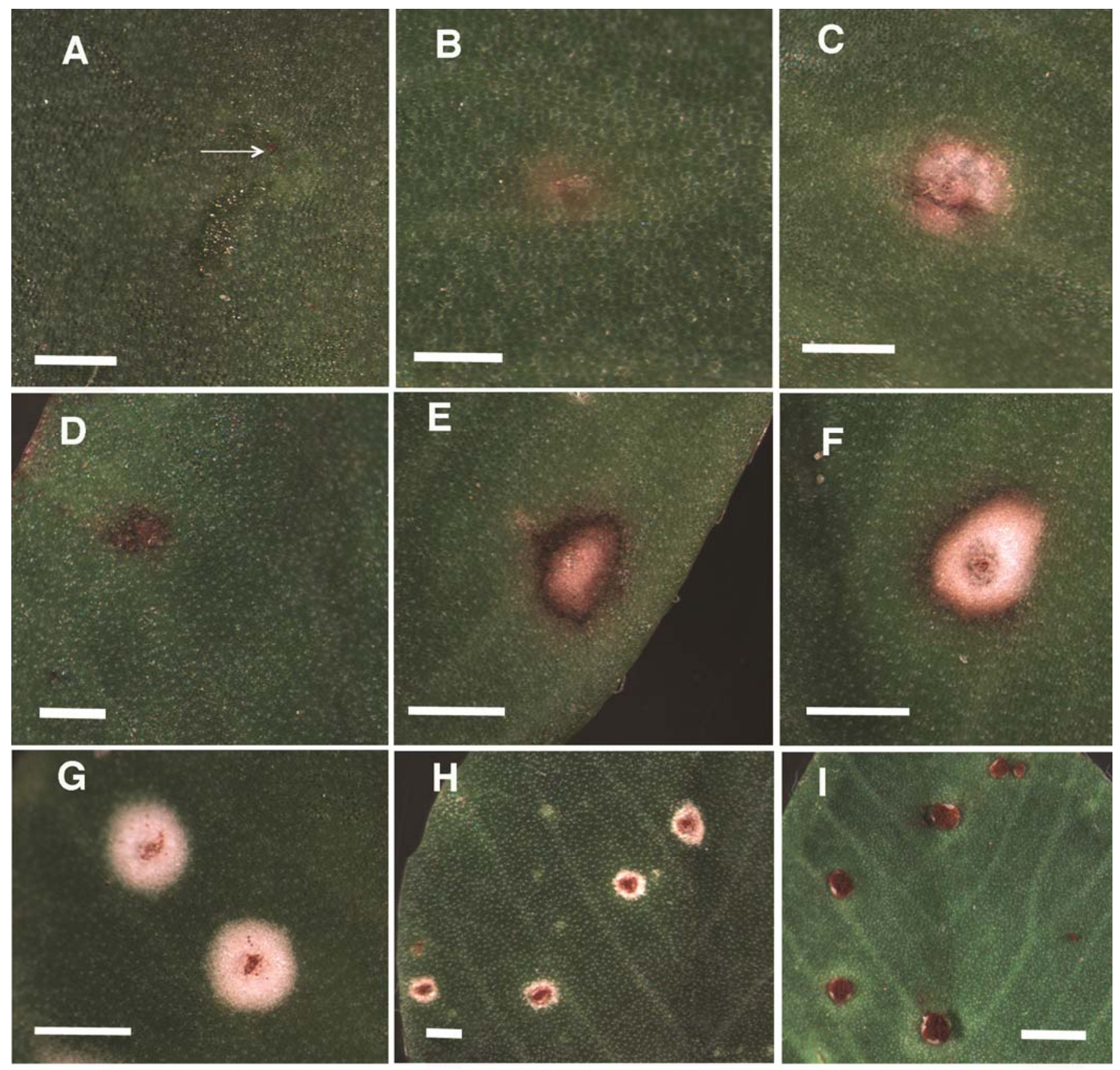

Fig. 5. Effect of curative $1 \times$ rate glyphosate treatment on symptoms of alfalfa rust. A, Water soaking observed on plants receiving the glyphosate treatment 2 to 6 days post inoculation (dpi). Arrow marks location of urediniospore. Bar $=0.5 \mathrm{~mm}$. B, White fleck observed on plants receiving the glyphosate treatment 2 to $6 \mathrm{dpi}$. Bar $=0.5 \mathrm{~mm}$. C, White fleck with aborted pustule observed on plants receiving the glyphosate treatment 2 to $6 \mathrm{dpi}$. Bar $=0.5 \mathrm{~mm}$. D, Necrotic fleck observed on plants receiving the glyphosate treatment 2 to $6 \mathrm{dpi}$. Bar $=0.5 \mathrm{~mm}$. E, Bleached lesion with dark border observed on plants receiving the glyphosate treatment 2 to $6 \mathrm{dpi}$. Bar $=1 \mathrm{~mm}$. F, Bleached lesion with closed pustule observed on plants receiving the glyphosate treatment 8 to $10 \mathrm{dpi}$. Bar $=1 \mathrm{~mm}$. G, Bleached lesion with small open pustule observed on plants receiving the glyphosate treatment $10 \mathrm{dpi}$. Bar $=1 \mathrm{~mm}$. $\mathrm{H}$, Bleached lesion with large open pustules on plants receiving the glyphosate treatment $12 \mathrm{dpi}$. Bar $=1$ $\mathrm{mm}$. I, Pustules on control without glyphosate $14 \mathrm{dpi}$. Bar $=1 \mathrm{~mm}$. 
Plants inoculated with rust 10 days after glyphosate application did not show statistically significant differences at 21 and 28 dpi. As observed in the previous experiment, the percentage of protected plants was higher with the $1 \times$ rate treatment than the $0.5 \times$ and $0.25 \times$ rate treatments (Fig. $2 B$ ). However, the $1 \times$ rate treatment resulted in $44 \%$ of plants being rated as protected at 14 dpi compared with $100 \%$ when plants were inoculated 3 days after glyphosate treatment. When plants receiving the $1 \times$ rate treatment were rated for disease at $21 \mathrm{dpi}$, only $3 \%$ had scores of 0 or 1 and, when rated at $28 \mathrm{dpi}$, there were no plants with scores of 0 or 1 .

Six glyphosate-tolerant alfalfa varieties varying in fall dormancy were tested to evaluate the level of rust resistance and control of rust over time after glyphosate application. Two varieties with high fall dormancy scores, DKA84-10RR and WL660RR, exhibited a low amount of genetic resistance to rust, with 13 and $25 \%$ plants, respectively, rated as resistant (score of 0 or 1) (Fig. 3A). The $2 \times$ rate glyphosate treatment was effective for rust control in all genetic backgrounds. The percentage of plants scored as protected from disease at 14 dpi was 88 to $100 \%$, depending on variety, when plants were inoculated 3 days after the glyphosate treatment. The protection was less effective when inoculation was delayed. When inoculated at 17 days after treatment, depending on variety, the percentage of plants scored as protected from disease at $14 \mathrm{dpi}$ ranged from 3 to $35 \%$ (Fig. 3B).

A $1 \times$ rate treatment of glyphosate was highly effective in preventing rust symptoms when applied to plants up to 10 days after inoculation (Fig. 4). For control water-treated plants, the first rust symptom, a small dark lesion, was observed at 8 dpi. At 10 dpi, small closed pustules were first visible and, by 12 dpi, open pustules had developed. Plants treated once with glyphosate at 2, 4, 6, or 8 dpi never developed pustules. Plants treated at 10 dpi had small closed pustules that did not develop further. All plants treated at 2 to $10 \mathrm{dpi}$ were rated as protected from disease at $14 \mathrm{dpi}$ (Fig. 4). A treatment at $12 \mathrm{dpi}$ did not have an effect on pustule development, and disease scores of these plants were similar to watertreated control plants. Leaves of glyphosate-treated plants showed a range of reactions to the curative treatment. Plants treated at 2 or 4 dpi had infrequent specks of water soaking, white flecks, or necrotic flecks (Fig. 5A-D). Plants treated at 6 or 8 dpi had more frequent bleached lesions with a dark border, and some had small closed pustules in the center of the lesion (Fig. 5E-F). Plants treated at 10 dpi frequently had bleached lesions with very small pustules that were visible only under magnification (Fig. 5G). Pustules of plants treated 12 dpi were visible by eye and were surrounded by a bleached border (Fig. $5 \mathrm{H}$ ). The pustules did not develop further after treatment and, whereas leaves of control plants had yellowed and fallen from the stem by $28 \mathrm{dpi}$, leaves of glyphosate-treated plants remained green.

\section{Discussion}

The results of greenhouse experiments demonstrated that glyphosate treatment has protective and curative effects on rust disease in glyphosate-tolerant alfalfa plants. Protective activity was greatest when plants were inoculated soon after glyphosate treatment. A $1 \times$ rate treatment was effective for at least 10 days and a $2 \times$ rate treatment was effective for at least 17 days. However, the proportion of protected plants was lower when inoculation occurred later. Previous research with glyphosate-tolerant wheat demonstrated systemic distribution of glyphosate (7) and protection from leaf rust infection for 14 days (7) or up to 21 days (1) after glyphosate treatment in controlled environments. When extended to field situations, glyphosate treatments of glyphosatetolerant wheat reduced early leaf rust infection but protection declined over time $(1,7)$. This was attributed to the observed decrease in glyphosate concentration in leaves, presumably from distribution through the plant and dilution by plant growth. A similar decrease over time in protection from soybean rust was observed in glyphosate-tolerant soybean treated with glyphosate (8). The decline in glyphosate effectiveness over time observed in treated alfalfa plants (Figs. 2 and 3) suggests that glyphosate also becomes less concentrated in alfalfa leaves over time. Our observation of increasing rust symptoms over time after a single inoculation suggests that glyphosate has fungistatic rather than fungicidal activity when applied before inoculation and that, once glyphosate levels have declined to a noninhibitory level, the fungus can continue to develop. Typically, urediniospores germinate during the $24 \mathrm{~h}$ after inoculation while at $100 \%$ relative humidity (28); therefore, it is unlikely that the pustules developing at later time points are from spores that germinated after glyphosate levels declined. This is supported by microscopic observations in which rust urediniospore germination was not inhibited by glyphosate treatment but arrest occurred soon after haustoria formation, without indication of fungal cell death (data not shown). Interestingly, when applied as a curative treatment after inoculation, glyphosate appears to have fungicidal activity. The necrotic and bleached lesions (Fig. 5) appear similar to a hypersensitive response, in which both pathogen and host cells are affected. Possibly, as $U$. striatus cells are killed because of disruption of the shikimate pathway after glyphosate application, the fungus releases molecules that trigger host defense responses, which lead to formation of the lesions observed. It is also plausible that death of fungal cells from glyphosate causes metabolic and physiological disruption of infected host cells, leading to plant cell death. If transcription of the transgene conferring glyphosate tolerance is disrupted in infected cells, then plant cell death could be caused by glyphosate. The mechanisms involved in protective and curative activity warrants further investigation.

Unlike wheat and soybean, in which season-long rust protection is needed, alfalfa foliage is harvested approximately every 25 to 35 days during the growing season. An alfalfa rust infection requires 10 to 14 days to develop a sporulating pustule, thus a glyphosate treatment soon after forage harvest would provide protective and curative activity to prevent rust symptoms for most of the growth period. Because there is little genetic resistance to rust in current alfalfa cultivars, the availability of glyphosate for control of rust in glyphosate-tolerant alfalfa provides an additional management tool for producers to reduce damage from this foliar pathogen.

Use of glyphosate for managing alfalfa rust is compatible with recommended weed management guidelines for glyphosate-tolerant alfalfa. Rust infections are most damaging in fall plantings (13). Glyphosate treatments are recommended for weed control in fall plantings soon after plant establishment and a second application after the fifth trifoliate leaf has developed but 5 days prior to a forage harvest (3). Based on our greenhouse studies, such treatments would also be effective for fall rust control. Use of glyphosate in established stands for rust control is also compatible with current management guidelines as long as only one application is made for each forage harvest, with no more than three applications per year for a total of 9.6 liters a.i./ha. In preliminary studies, we found that a glyphosate treatment provided protection from rust symptoms when applied to regrowth and plant stubble 7 days after foliage harvest. A $1 \times$ rate treatment applied 3 days prior to inoculation resulted in $100 \%$ protected plants scored at 21 dpi and $33 \%$ protected plants scored at $28 \mathrm{dpi}$ (data not shown).

The results of our experiments indicated that glyphosate treatments have limited effectiveness in protection against a hemibiotrophic fungal pathogen, $C$. trifolii, and no protection against a necrotrophic pathogen, $P$. medicaginis, although the frequency of the most severe disease symptoms was reduced by glyphosate treatment. This suggests that the fungus must be in intimate association with the plant for uptake of sufficient glyphosate to inhibit fungal growth. In previous in vitro studies, high concentrations of glyphosate were needed to inhibit mycelial growth of necrotrophic plant pathogens, including Fusarium solani f. sp. pisi and Pythium ultimum (12), Fusarium virguliforme (23), Rhynchosporium secalis and Pyrenophora teres (26), and Rhizoctonia solani (4). Interestingly, the activator adjuvants added to herbicides have been shown to have antifungal activity. Mycelial growth of Sclerotinia sclerotiorum was inhibited by several adjuvants when added to the culture medium but glyphosate alone had no effect on fungal growth (14). In the same study, mycelial growth was inhib- 
ited in assays in which soybean leaves were pretreated before inoculation by dipping into glyphosate with adjuvant but growth was not inhibited by pure glyphosate. This suggests that the curative activity we observed may be due, in part, to antifungal activity of the adjuvant in Roundup WeatherMax. Also, the reduced symptoms observed after C. trifolii and Phoma medicaginis inoculation could be due to residual antifungal activity of the adjuvant.

Our results suggest that glyphosate treatment may be a useful management tool for reducing damage from rust in glyphosatetolerant alfalfa and may have some activity against other foliar pathogens. Glyphosate would likely be useful for treating other biotrophic pathogens of alfalfa such as downy mildew (Peronospora trifoliorum) and dodder (Cuscuta spp.) (20). The effectiveness of glyphosate treatments for foliar disease control in the field remains to be tested.

\section{Acknowledgments}

We thank M. Dornbusch for excellent technical assistance; M. Tesfaye for assistance with statistical analysis; S. Temple, P. Reisen, P. Pierson, and J. Lamb for providing seed; and $\mathrm{K}$. Betts for providing equipment for glyphosate treatments.

\section{Literature Cited}

1. Anderson, J. A., and Kolmer, J. A. 2005. Rust control in glyphosate tolerant wheat following application of the herbicide glyphosate. Plant Dis. 89:1136-1142.

2. Anonymous. 2011. Record of Decision. Glyphosate-tolerant alfalfa events J101 and J163: request for nonregulated status. USDA-Animal and Plant Health Inspection Service. Online publication. http://www.aphis.usda.gov/ brs/aphisdocs/04_11001p_rod.pdf.

3. Anonymous. 2011. Technology use guide. Monsanto Company. Online publication. https://www.genuity.com/stewardship/Documents/2011_TUG. pdf.

4. Black, D. B., Russin J. S., Griffin, J. L., and Snow, J. P. 1996. Herbicide effects on Rhizoctonia solani in vitro and Rhizoctonia foliar blight of soybean (Glycine max). Weed Sci. 44:711-716.

5. Castell-Miller, C. V., Zeyen, R. J., and Samac, D. A. 2007. Infection and development of Phoma medicaginis on moderately resistant and susceptible alfalfa genotypes. Can. J. Plant Pathol. 29:290-298.

6. Dill, G. M., CaJacob, C. A., and Padgette, S. R. 2008. Glyphosate-resistant crops: adoption, use and future considerations. Pest Manage. Sci. 64:326331.

7. Feng, P. C. C., Baley, G. J., Clinton, W. P., Bunkers, G. J., Alibhai, M. F., Paulitz, T. C., and Kidwell, K. K. 2005. Glyphosate inhibits rust diseases in glyphosate-resistant wheat and soybean. Proc. Natl. Acad. Sci. USA 102:17290-17295.

8. Feng, P. C. C., Clark, C., Andrade, G. C., Balbi, M. C., and Caldwell, P. 2007. The control of Asian rust by glyphosate in glyphosate-resistant soybeans. Pest Manage. Sci. 64:353-359.

9. Gray, F. A. 1983. Assessment of foliage diseases in alfalfa in Wyoming. Plant Dis. 67:1156-1158.

10. Gray, F. A., Haaland, R. L., Clark, E. M., and Ball, D. M. 1980. Disease of alfalfa in Alabama. Plant Dis. 64:1015-1017.

11. Herrmann, K. M., and Weaver, L. M. 1999. The shikimate pathway. Annu. Rev. Plant Physiol. Plant Mol. Biol. 50:473-503.

12. Kawate, M. K., Kawate, S. C., Ogg, A. G., and Kraft, J. M. 1992. Response of Fusarium solani f. sp. pisi and Pythium ultimum to glyphosate. Weed Sci. 40:497-502.

13. Leath, K. T., Erwin, D. C., and Griffin, G. D. 1988. Diseases and nematodes. Pages 621-670 in: Alfalfa and Alfalfa Improvement. A. A. Hanson, D. K. Barnes, and R. R. Hill, eds. ASA-CSSA-SSSA, Madison, WI.

14. Lee, C. D., Penner, D., and Hammerschmidt, R. 2000. Influence of formulated glyphosate and activator adjuvants on Sclerotinia sclerotiorum in glyphosate-resistant and -susceptible Glycine max. Weed Sci. 48:710-715.

15. Mainer, A., and Leath, K. T. 1978. Foliar diseases alter carbohydrate and protein levels in leaves of alfalfa and orchardgrass. Phytopathology 68:1252-1255

16. Mould, M. J. R., Boland, G. J., and Robb, J. 1991. Ultrastructure of the Colletotrichum trifolii-Medicago sativa pathosystem. II. Post-penetration events. Physiol. Mol. Plant Pathol. 38:195-210.

17. National Alfalfa and Forage Alliance. 2011. Winter survival, fall dormancy and pest resistance ratings for alfalfa varieties, 2011 addendum. Online publication. http://www.alfalfa.org/pdf/2011VarietyLeafletAddendum.pdf.

18. Nutter, F. W., Guan, J., Gotlieb, A. R, Rhodes, L. H, Grau, C. R., and Sulc, R. M. 2002. Quantifying alfalfa yield losses caused by foliar diseases in Iowa, Ohio, Wisconsin and Vermont. Plant Dis. 86:269-277.

19. O'Neill, N. R. 1996. Pathogenic variability and host resistance in the Colletotrichum trifolii/Medicago sativa pathosystem. Plant Dis. 80:450457.

20. Reisen, P., Johannsen, N., and McCaslin, M. 2002. Dodder control in Roundup Ready alfalfa. Proc. 38th North Am. Alfalfa Improve. Conf. Davis, CA. Online publication. http://www.naaic.org/Meetings/National/ 2002meeting/2002Abstracts/Reisen.pdf.

21. Richards, T. A., Dacks, J. B., Campbell, S. A., Blanchard, J. L., Foster, P. G., McLeod, R., and Roberts, C. W. 2006. Evolutionary origins of the eukaryotic shikimate pathway: gene fusions, horizontal gene transfer, and endosymbiotic replacements. Eukaryot. Cell 5:1517-1531.

22. Rizvi, S. S. A., and Nutter, F. W. 1993. Seasonal dynamics of alfalfa foliar pathogens in Iowa. Plant Dis. 77:1126-1135.

23. Sanogo, S., Yang, X. B., and Scherm, H. 2000. Effects of herbicides on Fusarium solani $\mathrm{f}$. sp. glycines and development of sudden death syndrome in glyphosate-tolerant soybean. Phytopathology 90:57-66.

24. Sanyal, D., and Shrestha, A. 2008. Direct effect of herbicides on plant pathogens and disease development in various cropping systems. Weed Sci. $56: 155-160$.

25. Standard Tests to Characterize Alfalfa Cultivars. North American Alfalfa Improvement Conference. Online publication. www.naaic.org/stdtests/ index.html.

26. Turkington, T. K., Orr, D. D., and Xi, K. 2001. The influence of Roundup on in vitro growth and sporulation of Rhynchosporium secalis and Pyrenophora teres. Can. J. Plant Pathol. 23:307-311.

27. Von Chong, K., and Campbell, C. L. 1988. Seasonal occurrence of leaf spot pathogens of alfalfa in North Carolina. Plant Dis. 72:667-672.

28. Webb, D. H., and Nutter, F. W. 1997. Effects of leaf wetness duration and temperature on infection efficiency, latent period and rate of pustule appearance of rust in alfalfa. Phytopathology 87:946-950. 